\title{
El héroe exploratorio en El cuento del Grial de Chrétien de Troyes: una interpretación desde el pensamiento de Jordan Peterson
}

\author{
The Exploratory Hero in Perceval, the Story of the Grail \\ by Chrétien de Troyes: An Interpretation from \\ the Thought of Jordan Peterson \\ Enrique Sánchez-Costa \\ (Universidad de Piura, Lima)
}

\begin{abstract}
RESUMEN
Este artículo emplea el esquema de representación mitológica de Jordan Peterson (que deriva del análisis de los arquetipos de Jung) para tratar de ofrecer una interpretación novedosa de El cuento del Grial de Chrétien de Troyes. Se concluye que Perceval es el héroe exploratorio que se aventura en el mundo de lo desconocido (el bosque, lo inexplorado, el caos, la Naturaleza, la Gran Madre), para extraer conocimiento que revitaliza la tradición. Al afrontar lo desconocido (el dragón del caos) el héroe arriesga su integridad física y moral. Llega, incluso, a extraviar el ideal durante años, pero su humildad (su apertura cognoscitiva) le salva. Reconoce su ignorancia y renace espiritualmente. Cabe conjeturar, de acuerdo con la lógica interna de esta narración inacabada, que el héroe seguirá buscando la lanza y el Grial; hasta que, encontrándolos, cure la invalidez del Rey Pescador y devuelva la fecundidad a sus tierras (y de ese modo, simbólicamente, redima también a su padre de su muerte desgraciada y reverdezca las tierras de la Yerma Floresta). Así, Perceval, el héroe exploratorio, el conocedor, actualizará lo ya conocido (la caballería, lo explorado, el orden, la Cultura, el Gran Padre), transformándolo creativamente.
\end{abstract}

Palabras clave

Jordan Peterson; Chrétien de Troyes; héroe; Perceval; Grial; novela artúrica.

\section{Abstract}

This article uses Jordan Peterson's mythological representation scheme (derived from Jung's analysis of archetypes) to offer a novel interpretation of Chretien de Troyes' Perceval, the Story of the Grail. It concludes that Perceval is the exploratory hero who ventures into the world of the unknown (the forest, the unexplored, chaos, Nature, the Great Mother), to extract knowledge that revitalizes tradition. When facing the unknown (the dragon of chaos) the hero risks his physical and moral integrity. He even misses the ideal for years, but his humility (his cognitive openness) saves him. He acknowledges his ignorance and is spiritually reborn. It is to be conjectured, according to the internal 
logic of this unfinished narrative, that the hero will continue to search for the spear and the Grail; until, finding them, he cures the invalidity of the Fisher King and restores fertility to his lands (and in this way, symbolically, he also redeems his father from his disgraceful death and green the lands of the Barren Forest). Thus, Perceval, the exploratory hero, the knower, will update what is already known (chivalry, the explored, the order, the Culture, the Great Father), creatively transforming it.

\section{KEYWORDS}

Jordan Peterson; Chrétien de Troyes; hero; Perceval; grail; arturic novel.

Recibido: $12 / 05 / 2021$

Aceptado: $11 / 11 / 2021$

\section{Introducción}

Chrétien de Troyes, a quien García Gual considera «el primer gran novelista europeo» (García Gual, 1986: 103) y Carlos Alvar «el primer gran narrador de las literaturas románicas» (Chrétien, 2013: XI), revolucionó con su obra la literatura occidental. Pocos escritores han sido tan pioneros y transformadores como él. En sus cinco romans, escritos en apenas dos décadas (c. 1165-1182), el narrador y trouvère de la Champaña fue el primero que incorporó la concepción trovadoresca del amor - la fin'amors - a la narración. Y fue también el primero que, inspirado en la Historia Regum Britanniae (c. 1138) de Geoffrey de Monmouth y el Roman de Brut (1155) de Wace, desarrolló el mundo artúrico en la narrativa de ficción.

Entre las obras de Chrétien, ninguna impactaría tanto en la literatura como su último roman: Li contes del graal (El cuento del Grial) (Fig. 1). Escrito en verso, en francés antiguo, hacia 1180 (y que Chrétien dejará inconcluso, al sorprenderle la muerte), fue el primer Bildungsroman de la literatura europea. Y, más importante todavía, inauguró un mito literario (Perceval y el Grial) que durante cinco décadas sería reinterpretado y reescrito febrilmente por autores medievales (como Robert de Boron y Wolfram von Eschenbach), y que perviviría en el arte moderno en manifestaciones diversas como, por ejemplo, el Parsifal (1882) de Wagner.

Cirlot, que valora la última narración de Chrétien como «la culminación de toda su obra anterior» (2014: 23), apunta, con relación al mito del Grial, que «en Chrétien de Troyes ya estaban contenidas todas las posibilidades significativas que los escritores posteriores supieron desplegar en sus obras respectivas $\gg(16)$. El cuento del Grial, como todas las obras maestras, se resiste a una interpretación unívoca y cerrada. Al contrario: en lo que afirma y en lo que calla, en su ironía y ambigüedad, es una obra que favorece continuas relecturas y que - como afirmaba Italo Calvino de los clásicos— «nunca termina de decir lo que tiene que decir» (Calvino, 2015: 15). 


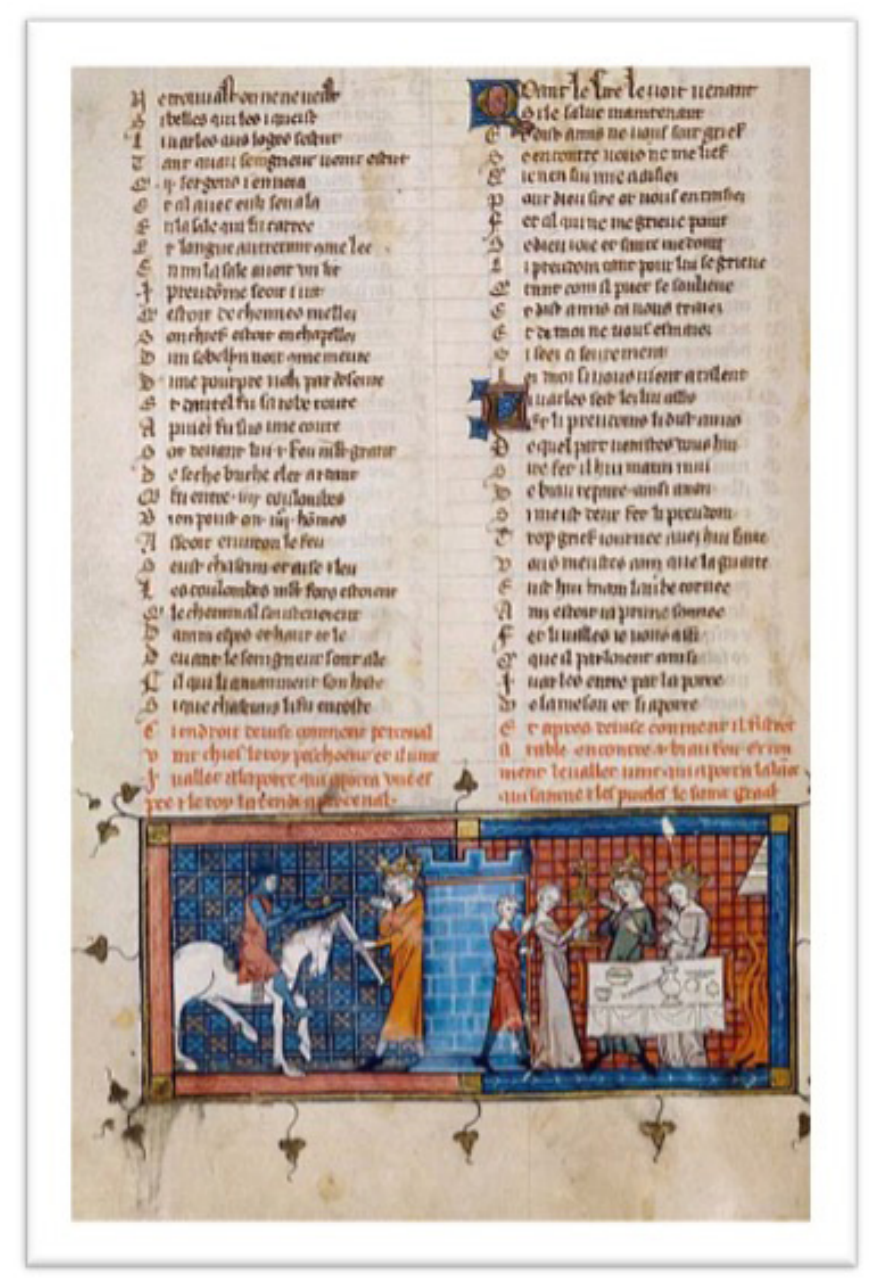

Fig. 1. Perceval ou Le Conte du Graal. BnF Français 12577, fol. 18v.

La crítica ha abordado El cuento del Grial desde múltiples perspectivas. En 1938 Burdach relacionó la escena del Grial con la liturgia cristiana oriental: «Los elementos escénico-dramáticos de la saga del Grial, de la procesión del Grial, tuvieron su origen en la misa bizantina» (Cirlot, 2014: 82). Esta liturgia (que influiría en la liturgia católica) enfatizaba dramáticamente la Pasión de Cristo y concedía mucha importancia a la procesión de las ofrendas y a la lanza de Longinos. De hecho, el interés por la lanza no era solo importante en Constantinopla (que custodiaba en Santa Sofía, desde el año 615, su punta) sino en toda la cristiandad. Es conocido el impacto que provocó el «descubrimiento» de esa lanza en una iglesia de Antioquía, en 1098, durante la Primera Cruzada.

La relación entre el Grial y las Cruzadas fue explorada en profundidad por Helen Adolf. Atendiendo al contexto histórico en el que fue escrita la novela (la inminente caída del Reino Latino de Jerusalén), Adolf señaló en 1960 que «the Grail legend is a fruit of the Crusades. More precisely, the legend owes its development to the transformation of the crude Crusading creed, with its reliance on "fetishes" (relics), into a religion of personal experience supported by symbols» (1960: 11). ${ }^{1}$

1. Pocos años después, Martín de Riquer concibió el castillo del Grial como «trasunto del Reino de Jerusalén [...] Li contes del Graal sería una extensa e impresionante “canción de cruzada”, con trama y asunto novelesco» (Riquer, 1968: 131-132). 
De hecho, Chrétien escribió su libro por encargo del conde Felipe de Flandes, quien moriría por enfermedad en Acre en 1191. Unos años antes, en 1177, el rey de Jerusalén Balduino IV (el Leproso) había ofrecido a su primo Felipe la administración del reino. El conde, por razones poco claras, rechazó el ofrecimiento. Este es el episodio enigmático que, según Helen Adolf, habría inspirado la escena del castillo del Rey Pescador y el silencio de Perceval ante el paso del Grial. ${ }^{2}$

Se ha señalado el simbolismo masculino (fálico) de la lanza y femenino (receptor) del Grial. También se ha conectado El cuento del Grial con las mitologías orientales (los rituales de los cambios estacionales y de fecundación o la historia egipcia de Isis y Osiris). Y se han encontrado paralelos con las mitologías célticas, que habrían podido llegar a Chrétien a través de narraciones de bardos bretones. En especial, se ha destacado un relato irlandés, Éxtasis profético del fantasma, que presentaría las siguientes semejanzas con la novela de Chrétien: «1. La visita del héroe al otro mundo/castillo del Grial; 2. La presencia de la copa/Grial; 3. Las preguntas que hay que realizar (la Soberanía/Perceval); 4. La presencia de la doncella Soberanía/portadora del Grial» (Cirlot, 2014: 77$){ }^{3}$

Es posible que Chrétien no conociera la narración irlandesa, ni la de Isis y Osiris, ni tantas otras que se han propuesto como inspiración de su última obra. Al fin y al cabo, son incontables las semejanzas y los patrones comunes entre relatos mitológicos de culturas que no tuvieron ningún contacto entre sí. ${ }^{4}$ Jung explicó esas coincidencias a partir del «inconsciente colectivo» universal, presente en toda psique, cuyos contenidos son los instintos y los «arquetipos». Para Jung, la mente, lejos de ser una «tabula rasa, contiene imágenes primordiales, predisposiciones, formas y aun ideas en sentido platónico». Y esos arquetipos, al ser innatos, «pueden volver a surgir espontáneamente en toda época y lugar sin ser influidos por ninguna transmisión exterior» (1970: 73). Los arquetipos - explica - no pueden ser percibidos directamente, sino a través de las imágenes y símbolos que hacen surgir, así como de sus patrones comunes.

Más allá de las relaciones de transtextualidad presentes en El cuento del Grial, más allá de su recepción pasada o presente, el texto que inició el mito literario del Grial sigue ofreciendo potencialidades semánticas inagotables. El poeta romántico alemán Joseph von Eichendorff escribió que «el mundo empieza a cantar, | si das con la palabra mágica» (Safranski, 2012: 17). También los mitos literarios, para brindar nuevas significaciones, necesitan ser descifrados desde enfoques conceptuales novedosos. De ahí la conveniencia de releer el texto de Chrétien desde la propuesta teórica de Jordan Peterson, psicólogo de la Universidad de Toronto y autor de Maps of Meaning. The Architecture of Belief (1999). A partir de los arquetipos junguianos, la psicología evolutiva o la neurociencia, Peterson explora en su libro los relatos míticos y religiosos, así como los marcos o mapas de sentido en los que esos relatos se inscriben y que, al mismo tiempo, contribuyen a configurar.

El enfoque interdisciplinario de Peterson nos permitirá analizar El cuento del Grial desde nuevos horizontes semánticos. Seguiremos la infancia paradisíaca del héroe, aislado (como el jardín

\section{Cfr. Cirlot, 2014: 19-40}

3. En este trabajo, siguiendo la práctica de otros muchos autores, denominaremos el roman courtois de Chrétien como «novela», aun siendo conscientes de que sus romances son una forma temprana e idealizada de novela, la cual deberá madurar hasta cristalizar en la novela realista de la Edad Moderna.

4. En este sentido, escribe Blumenberg: «Si damos por supuesto que el problema principal de una mitología es, realmente, entender cómo los contenidos míticos se asemejan tanto en todos los sitios del mundo, entonces no puede ser de menos peso la circunstancia de que, sorprendentemente, también en la dimensión temporal, de un extremo al otro de la historia humana, permanezcan tan constantes» (2003: 298). 
del Edén o la infancia de Buda) de la experiencia del sufrimiento, la vulnerabilidad humana y la mortalidad. El abandono de su madre por parte de Perceval: el fallo inicial, la hamartía de la que se derivarán errores posteriores. La entrada del protagonista en el bosque oscuro (símbolo de lo desconocido y de su potencial). La acogida de Perceval en la corte de Arturo (representación de lo conocido, el rey sabio, el Gran Padre, la tradición). El aprendizaje del adolescente y su identificación con el grupo caballeresco. La pasividad culpable de Perceval ante el cortejo de la lanza y el Grial. Su compromiso a una quête perpetua, en busca de la fuente última de lo sagrado. El extravío de Perceval y su metanoia, confesión y comunión el día simbólico de Pascua. Y plantearemos el desarrollo posible de esta novela inacabada, considerando a Perceval -desde la teoría de Peterson- como héroe exploratorio: quien, tras sumergirse peligrosamente en lo desconocido, renueva con su conocimiento la cultura y la sociedad.

\section{La arquitectura de los mitos en Jordan Peterson}

La ciencia describe el mundo como un ámbito de objetos, despojado de toda emoción y subjetividad. Trabaja de modo aséptico, frío, realizando experimentos medibles y replicables, y proponiendo conclusiones falsables. En cambio - explica Peterson- la literatura y el mito consisten en «narrative representations of behavioral patterns» (1999: 103). El ser humano actúa y, con el paso del tiempo, visualiza patrones en sus actos. El mito representa dichos patrones de conducta: tanto los modélicos (los heroicos, los que conducirían al éxito evolutivo de la especie) como los antimodélicos (los que, si se reproducen, impiden el desarrollo individual y de la especie).

El mito precede y sirve de matriz — de suelo nutricio- de las abstracciones que cristalizarán más tarde en forma de conceptos y teorías. Es decir, el mito media entre el comportamiento humano (y sus patrones) y su posterior descripción conceptual. De ahí que el mito represente la experiencia humana como «drama, story, forum for action» (Peterson, 1999: 105). El mundo del mito, por tanto, no es fáctico, sino dramático, ético y conductual: «the world of value-what is and what should be, from the perspective of emotion and action» (xxi). En la narración mítica lo objetivo y lo subjetivo se entreveran: todo lo que existe significa, y su significado moral (cómo afecta al observador, en términos emocionales y de comportamiento) condiciona lo que algo es. En definitiva, «the mythic universe is a place to act, not a place to perceive» (9).

Veamos, a través de una cita extensa de Peterson, cuál es para él la estructura ternaria de la representación mítica de la experiencia humana:

Mythological representations of the world-which are representations of reality as a forum for action-portray the dynamic interrelationship between all three constituent elements of human experience. The eternal unknown—nature, metaphorically speaking, creative and destructive, source and destination of all determinant things-is generally ascribed an affectively ambivalent feminine character (as the «mother» and eventual «devourer» of everyone and everything). The eternal known, in contrast—culture, defined territory, tyrannical and protective, predictable, disciplined and restrictive, cumulative consequence of heroic or exploratory behavior-is typically considered masculine (in contradistinction to «mother» nature). The eternal knower, finally-the process that mediates between the known and the unknown-is the knight who slays the dragon of chaos, the hero who replaces disorder and confusion with clarity and certainty, the sun god who eternally slays the forces of darkness, and the «word» that engenders cosmic creation. (1999: 20) 
Peterson combina estos tres elementos constitutivos de la experiencia humana (lo desconocido, lo conocido y el conocedor) con los principios de orden y caos que, como el yin y el yang, articulan también el mundo. El orden es lo conocido, el territorio explorado, y está representado en la figura patriarcal del Gran Padre: es la tradición, la cultura, las leyes, la jerarquía, el dogma; es lo consciente, lo racional, lo apolíneo, el sol; es la autoridad, el rey sabio y benefactor; pero también es el gigante, el ogro, la represión, lo viejo o el rey tiránico. El caos es lo desconocido, el territorio inexplorado, y está representado en la figura matriarcal de la Gran Madre: es la matriz, la fecundidad, lo joven; es la emoción, lo sensual; es lo dionisíaco, lo anárquico; es lo misterioso y el inconsciente; es la luna, la cueva, el vientre de la ballena; es la reina y el extranjero; es el cambio, la revolución; pero también es la bruja, la madre sobreprotectora, la madrastra malvada o el peligro.

Tal como argumenta Peterson en su libro, necesitamos el orden, lo conocido, la tierra firme. Necesitamos identificarnos con un grupo o cultura que nos aporte seguridad; que nos provea de coordenadas axiológicas claras; que nos proteja de la paralización, el miedo y la ansiedad que nos provocan tanto lo desconocido como el cambio. Ahora bien, el orden tiene también una vertiente tiránica, autoritaria, totalitaria. El orden excesivo degenera en parálisis, en anacronismo; en inadaptación ante el cambio y la evolución de la realidad. El orden patológico (visible políticamente en el fascismo o el estalinismo) impide la creatividad, la espontaneidad, la disidencia; impide la apertura y la renovación necesarias ante la complejidad del mundo.

El exceso de orden, para Peterson, es dañino. Pero también lo es el exceso de caos: la anarquía, la disolución en la multiplicidad; la decadencia, la creatividad sin un punto de partida, un proyecto y una meta. Por ello, deben armonizarse el orden y el caos. ¿Quién puede, entonces, reconciliar el orden y el caos, lo conocido y lo desconocido, el Gran Padre y la Gran Madre? Esa es la misión y el camino vital del conocedor: del héroe exploratorio, del héroe revolucionario, del renovador de la sociedad. Así lo expone Peterson:

The exploratory hero, divine son of the known and unknown, courageously faces the unknown, unites with it creatively—abandoning all pretense of pre-existent «absolute knowledge»-garners new information, returns to the community, and revitalizes his tradition. [...] The hero, the savior, is metaphorical or narrative description of the pattern by which the existence of anomalous information is accepted, mined for significance, and incorporated into the body of cultural adaptation. (1999: 176 y 358 )

\section{Infancia paradisíaca y formación juvenil del héroe}

El cuento del Grial se abre con un locus amoenus, un lugar y tiempo de delicias: «En el tiempo en que los árboles florecen, echan hojas los bosques, reverdecen los prados, los pájaros en su latín cantan con dulzura al amanecer y todas las cosas se inflaman de alegría». Allí, en ese paraíso, «el hijo de la Dama Viuda del Bosque Devastado se levantó un día» (Chrétien, 2013: 460). Vemos el mundo desde los ojos del niño: con la frescura propia de la inocencia. Ahora bien, incluso bajo esta visión idílica asoma lo ominoso: la muerte del padre y la devastación del bosque. Y es que, como sabremos pronto, la Dama Viuda ha visto morir a su esposo y a sus dos hijos mayores en hechos de armas, por lo que ha alejado a su último hijo de todo contacto con la sociedad caballeresca.

La Septuaginta traduce el hebreo (jardín del) «Edén» con el término griego paradeisos ( $\pi \alpha \rho a ́ \delta \varepsilon เ \sigma o \varsigma)$, que proviene en su origen del avéstico pairi-daêza (recinto amurallado), utilizado en el Imperio persa para referirse a sus grandes jardines cercados. Al fin y al cabo, todo estado de 
felicidad perfecta debe estar vallado frente a la intromisión del sufrimiento. En el relato bíblico —explica Peterson-, Adán y Eva están «sheltered in an eternally productive garden, blissfully ignorant of their essential nakedness and vulnerability» (1999: 291). Ese estado de perfección es trastornado por su caída, por su desobediencia a Dios, que les golpea con la autoconciencia de su desnudez, vulnerabilidad física y mortalidad. Y es que, para la visión mitológica del mundo, «cognitive transformations alter the structure of existence - change the very relationship between heaven and earth, creator and created; permanently restructure the cosmos itself $\gg(291)$.

También Buda inició su vida en un jardín de delicias amurallado. El padre aisló durante años a su hijo -el Príncipe Gautama - de todo contacto con el sufrimiento y la tragedia. Solo los jóvenes, saludables y felices podían acceder al jardín. Hasta que un día el hijo decidió salir y ver el mundo, y los dioses le mostraron (a través de personas que interrumpían su camino) la vejez, la enfermedad y la muerte. Para Peterson, «the myth of the Buddha is the story of individual development, considered in the ideal» (1999: 292). Todo niño, en sus primeros años, está protegido por sus padres de lo trágico. Pero el muro protector debe reducirse poco a poco, para que el hijo conozca la realidad del mundo y pueda convertirse en una persona autónoma y productiva. ${ }^{5}$

Igual que el padre de Buda, la madre del héroe de El cuento del Grial aísla a su hijo de los peligros del mundo, en la «Yerma Floresta Solitaria» (Chrétien, 2013: 460). La Dama Viuda encarna así el arquetipo de la madre devoradora: la que, en su amor sobreprotector, devora el potencial del hijo, al recluirlo en la infancia perpetua. Tan ignorante es el chico de la realidad del mundo que un día, cuando se topa en el bosque con cinco caballeros, por sus armaduras resplandecientes piensa que son ángeles. Tan necias son sus preguntas, que uno de los caballeros exclama: $\ll_{i}$ Eres demasiado simple!» (462). Y cuando el caballero pregunta al hijo su nombre, este responde: «Me llamo Bello Hijo» (465). Su madre le comentará, poco después, que «por el nombre se conoce al hombre» (468). Perceval todavía no conoce su propio nombre, porque vive en un estado mental propio de la primera infancia, caracterizado por la inconsciencia sobre sí mismo y sobre el mundo.

Cuando el hijo cuenta a la madre su encuentro con los caballeros, esta se desmaya. Una vez recobrada, le dice: «Bello dulce hijo, pensaba guardaros de la caballería tan bien que nunca oyeseis hablar de ella y que no vierais a ninguno de ellos» (466). Confiesa al hijo el linaje insigne de su padre - gran caballero - y el de ella misma. Algo que, por cierto, emparenta a Perceval con muchos otros héroes, que ignoran durante años su linaje excepcional. La madre cuenta entonces al hijo cómo su padre «fue herido entre las piernas de tal modo que quedó tullido en el cuerpo» (466), perdió sus tierras y riquezas. «Las tierras fueron devastadas y las pobres gentes, envilecidas» (467). Los otros dos hijos de la familia fueron nombrados caballeros y murieron en hechos de armas. El padre murió después de tristeza, por la pérdida de esos hijos.

La Dama Viuda asume en su discurso la actitud resignada ante la decadencia de la sociedad: «Los mejores han decaído, mientras que «maldad, afrenta o pereza no caen» (466). Ya solo le queda el consuelo de refugiarse en su hijo, al que pide que no la abandone. Pero «el muchacho escucha muy poco lo que su madre le dice» (467) y parte a la corte de Arturo a hacerse nombrar caballero. Cuando se había alejado unos metros de casa, «miró y vio caída a su madre al cabo del puente, al otro lado, y yacía desvanecida como si hubiera caído muerta» (469). Pero Perceval ignora a su madre yacente: «Golpea con la vara al caballo en la grupa y se aleja [...] muy rápido por

5. Buda, tras muchos sacrificios, alcanzará el nirvana. Y renunciará pronto a esa felicidad estática para extender su mensaje en el mundo. Para Peterson, «it is this latter action that truly marks him as a revolutionary hero. Acquisition of wisdom - the consequence of the creative endeavor - is insufficient. The circle of redemptive action is not closed until information hard won on the battleground of the individual psyche has been integrated into the larger community» (1999: 294). 
el gran bosque oscuro» (470). No atender a su madre desvanecida será el pecado que marcará la historia posterior de Perceval. Él, inconsciente ahora de su falta, se lanza al encuentro de la aventura: lo imprevisible, lo que adviene. ${ }^{6} \mathrm{Y}$ se interna en el bosque oscuro, símbolo de lo desconocido: todo peligro y, al mismo tiempo, todo potencial.

En el camino hacia la corte de Arturo, el muchacho besa a la fuerza a una dama que encuentra en el camino, interpretando torpemente las recomendaciones de su madre de tratar con cortesía a las mujeres. Una vez en la corte, algunos se ríen de su desconocimiento absoluto del mundo caballeresco. Pero Arturo sabe apreciar el potencial del chico: $\ll$ Si el muchacho es simple y torpe, podría ser hombre muy gentil; y si ha sido por su aprendizaje, porque haya tenido mal maestro, aún puede ser noble y prudente» (476). Arturo simboliza en la novela artúrica el rey sabio y benevolente, la versión positiva del Gran Padre (la versión negativa es el tirano: cruel, injusto y totalitario). Para Peterson, el arquetipo del rey sabio ofrece «cultural protection from the terrible forces of nature, security for the weak, and wisdom for the foolish» (1999: 90).

\begin{abstract}
The wise king maintains stability, not because he is afraid of the unknown, but because nothing new can be built without a strong foundation. He is the adaptive routine, developed by the heroes of the past, whose adoption by those in the present allows for control and safety. He is a house with doors; a structure that shelters, but does not stifle; a master who teaches and disciplines but does not indoctrinate or crush. He represents the tradition fostering cooperation among people whose shared culture makes trust possible.
\end{abstract} (1999: 208)

El rey sabio es, en la concepción medieval, la figura patriarcal que vela por la seguridad física y espiritual del reino. Las cortes de Arturo (Carduel, Carleon y especialmente Camelot) representan el espacio material y espiritual de orden, seguridad y armonía. La corte artúrica protege frente al caos, los peligros de la naturaleza y las amenazas que laten en lo inexplorado y lo desconocido (simbolizadas en los monstruos de los mapas medievales sobre la terra incognita). Pero, como veremos, permanecer siempre en la corte, en el espacio del orden, no es una opción válida. Porque el conocimiento, si no se actualiza, se vuelve desfasado: incapaz de afrontar los cambios y los peligros del mañana. Por eso abandonan los caballeros artúricos la corte, en busca de aventuras y - en el caso de Perceval — en busca de nuevo conocimiento.

En la corte artúrica el Caballero Rojo ultraja a la reina y al rey. El chico, que desea sus armas bermejas, lo desafía en duelo y lo mata lanzándole una jabalina en el ojo. Su actuación, nada caballeresca pero efectiva, causa sorpresa entre los nobles. De nuevo, «se lamenta y queja el rey de que el chico no sabe ni poco ni mucho de armas ni de ninguna otra cosa, y sugiere que habría sido un buen caballero, sin duda, quien hubiera enseñado y adiestrado al muchacho» (Chrétien, 2013: 481). Esa petición la asumirá poco después un caballero anciano, Gornemans de Goort, quien instruye al joven en los modales corteses y en el manejo de las armas. El narrador destaca la rapidez con la que el joven aprende, «pues le venía por naturaleza» (484). De hecho, el mismo Perceval manifiesta su deseo de conocer: «Nunca vieron mis ojos nada por lo que tuviera tanto deseo. Me gustaría mucho saber tanto como vos sabéis» (484).

6. Tal como ha escrito Cirlot, «en la novela artúrica la totalidad de la vida se concibe como una aventura. [...] La aventura caballeresca instaura un diálogo entre la interioridad del individuo, que empieza a ser atisbada, y el mundo exterior transfigurado en signo viviente, al tiempo que acepta la vida como el riesgo constante al que se somete el individuo repleto de fe» (2007: 40). El caballero errante -señala la misma autora- debe «confrontarse con el mundo, ofrecerse para que el mundo hable» (39). 
La adolescencia implica, a menudo, abandonar el manto protector de los padres, aunque no se esté todavía preparado para lanzarse a los caminos del mundo. Para alcanzar la madurez, el adolescente necesita vivir una etapa intermedia de aprendizaje. Durante esta etapa, las autoridades de su grupo social le protegen de la exposición excesiva a lo desconocido, le inculcan una identidad cultural y le preparan para ser luego, a su vez, un miembro autosuficiente y beneficioso de la sociedad. Peterson, reflexionando sobre la etapa de aprendizaje, apunta:

Identification with the group means the provision of determinate meaning, as the antidote to excruciating ignorance and exposure to chaos. [...] These patterns of behavior and hierarchies of value - which children mimic and then learn expressly— give secure structure to uncertain being. (1999: 223)

Para alcanzar la maestría moral y profesional, el adolescente necesita, primero, formar su inteligencia y disciplinar su voluntad. No hay mística sin ascesis previa. No hay libertad fructífera sin obediencia previa a una disciplina y un ideal ${ }^{7}$.

\section{Fracaso de Perceval ante el Grial y compromiso de búsqueda perpetua}

Tras el tiempo de aprendizaje (clave en este Bildungsroman), Gornemans de Goort arma caballero a Perceval. Se cumple así el rito de paso que marca, para los aristócratas de su tiempo, el acceso a la vida adulta. Y le da un último consejo al caballero novel: «Procurad no ser hablador ni chismoso. [...] os prevengo frente al hablar demasiado» (Chrétien, 2013: 487). Luego, Perceval, acordándose de su madre, se encamina hacia su casa. En el trayecto, derrota a los asediadores de un castillo y se enamora de la doncella liberada: Blancaflor. Pronto retoma el camino hacia la casa materna, hasta que, en un río, dos pescadores le invitan a pasar la noche en un misterioso castillo. Allí es agasajado por un caballero anciano e inválido, que le regala una espada. Mientras hablan, atraviesa la sala un criado portando una lanza blanca de hierro, de cuya punta mana una gota de sangre. A continuación, aparecen otros dos hermosos criados con candelabros de oro. En el mismo cortejo,

una doncella que venía con los criados, bella, agradable y bien ataviada, sujetaba entre las dos manos un Grial. Cuando entró allí con el Grial que llevaba sobrevino tan gran claridad que todas las velas perdieron su luz como las estrellas y la luna cuando sale el sol. Detrás de ella venía otra que llevaba un plato de plata. El Grial, que iba delante, era de fino oro puro; tenía piedras preciosas de muchas clases, de las más ricas, de las más caras que hay en el mar y en la tierra: a todas las demás piedras superaban las del Grial, sin duda. Igual que la lanza, pasaron por delante de él y fueron de una habitación a otra. El muchacho los vio pasar y no se atrevió a preguntar a quién servían con el Grial, pues él siempre recordaba en el corazón las palabras del noble sabio. (512) (Fig. 2)

\footnotetext{
7. Peterson, al hablar de la necesidad de la obediencia para la productividad, cita este pasaje de Nietzsche: «Lo esencial "en el cielo y en la tierra” es, según parece, repitámoslo, el obedecer durante mucho tiempo y en una única dirección: con esto se obtiene y se ha obtenido siempre, a la larga, algo por lo cual merece la pena vivir en la tierra, por ejemplo virtud, arte, música, baile, razón, espiritualidad, -algo transfigurador, refinado, loco y divino» (Nietzsche, 2001: 127).
} 


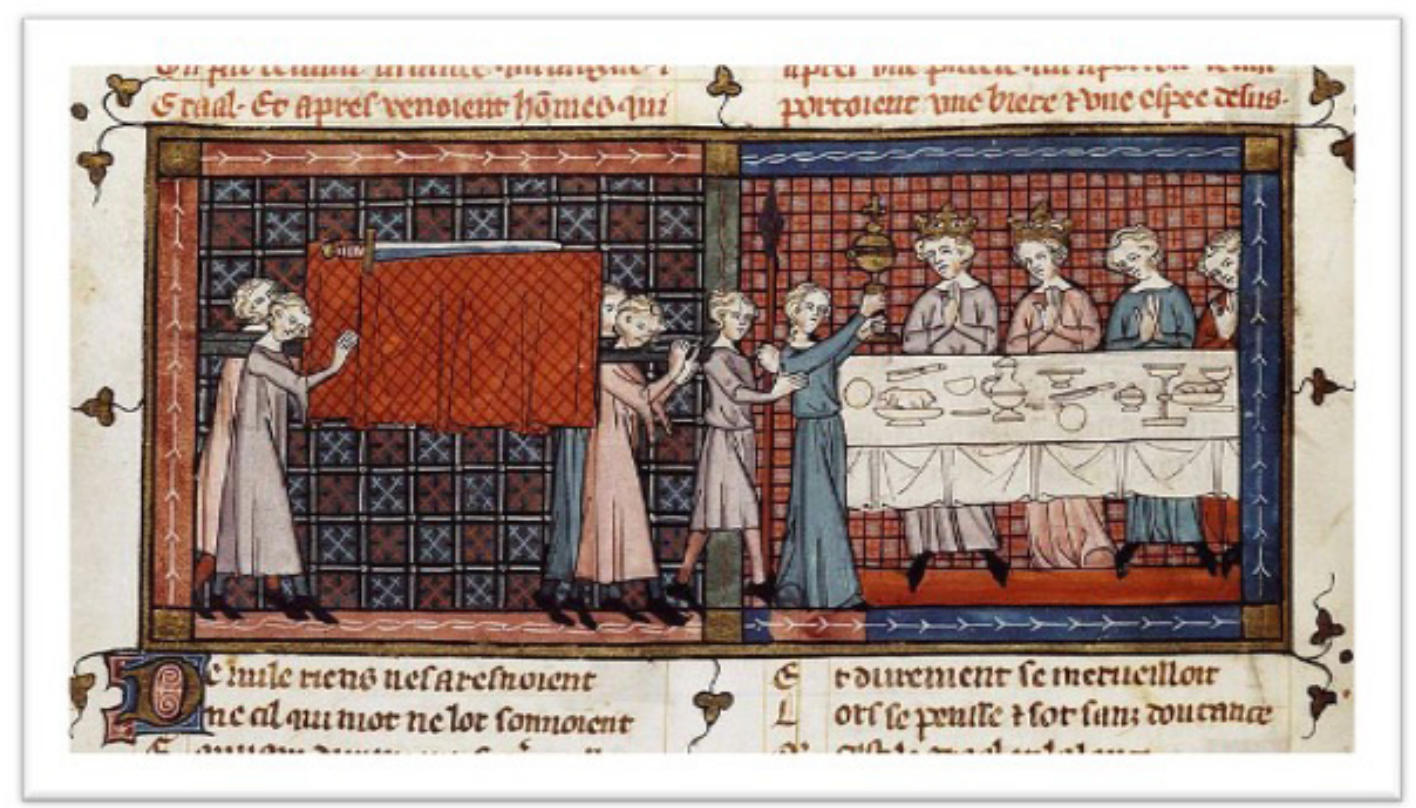

Fig. 2. Perceval ou Le Conte du Graal. BnF Français 12577, fol. 74v.

El Grial, entonces un simple plato de cocina, se transforma desde este pasaje de Chrétien en un objeto trascendente, que iniciará un fecundo mito literario. Se repite aquí varias veces el término graal (resonante fonéticamente), así como, durante la cena, desfilará varias veces el cortejo del Grial ante Perceval. Pero este, aplicando mecánicamente el consejo de su maestro, no pregunta ni una sola vez sobre la lanza o el Grial. Como hemos visto, es necesario el aprendizaje de la tradición para el desarrollo del individuo y la pervivencia de una cultura. Pero también los sistemas de pensamiento tienen su vertiente oscura. Como advierte Peterson, «systems of belief and moral action - and those people who are identified with them - are concerned above all with self-maintenance and preservation of predictability and order» (1999: 216). Aplicar un sistema de valores es útil en situaciones normales, pero puede resultar ineficaz - e incluso contraproducente- ante el encuentro con lo anómalo e imprevisible. La emergencia de lo nuevo reclama ser abordada desde un enfoque que incorpore, y al mismo tiempo supere, la sabiduría tradicional.

A la mañana siguiente del paso del cortejo del Grial, Perceval despierta solo en el castillo. Se interna de nuevo en el bosque, hasta que encuentra una doncella. Esta le cuenta que el dueño del castillo es el Rey Pescador, y que está inválido porque, en un combate, «fue alcanzado por una jabalina entre los dos muslos» (Chrétien, 2013: 516). Conversan sobre la escena del Grial y la doncella le reprocha no haber preguntado por qué sangra la lanza ni a quién se sirve con el Grial. Entonces, «él, que no sabía su nombre, lo adivina y dice que se llama Perceval el Galés» (517). El muchacho toma conciencia de sí mismo (de su nombre) tras evidenciarse su error de no preguntar. Como en el relato genésico, el autoconocimiento está unido a la manifestación de la vulnerabilidad y la culpa. La doncella le recrimina: «Qué infortunado eres por todo lo que no has preguntado, pues hubieras reparado tantas cosas que el buen rey que está tullido habría recuperado el poder de sus miembros y de su tierra» (518). Le cuenta que ella es su prima hermana, que la madre de Perceval ha fallecido y que su silencio ante el Grial se debe al pecado de no socorrer a la madre, que «murió de dolor por ti» (518). 
De nuevo en el camino, Perceval derrota a otro caballero (el Orgulloso de la Landa) y le manda presentarse a la corte artúrica. En la corte, Galván, el caballero prototípico, proclama que no conoce a ningún caballero como Perceval, «que pueda compararse con este en armas y valor» (523). El rey Arturo jura que, por lo bien que le ha servido, «no pasaré dos noches seguidas en habitación ni en sala hasta que lo vea, si está vivo, en el mar o en tierra, y me pondré en marcha para buscarlo» (526). El tirano es el ensoberbecido que, como el Lucifer de John Milton, considera su conocimiento completo e infalible. De ahí que, en palabras de Peterson, «the tyrant is the force of everything that has been, including everything that once was good, against everything that could be» (Peterson, 1999: 213). La autocomplacencia cognoscitiva del tirano le lleva a descartar toda nueva información y toda crítica, lo que genera coerción, parálisis y, finalmente, decadencia personal y social. El rey sabio, en cambio, sabe que su conocimiento es parcial y falible, por lo que se pone en marcha en busca de nuevo conocimiento (como hace Arturo, que parte con su corte en busca de Perceval).

Nuestro héroe, por su lado, sigue interesado en buscar aventuras y duelos ${ }^{8}$. En el pasaje más lírico de la novela, Perceval ve en el camino tres gotas de sangre en la nieve, que han brotado del cuello de un ganso herido. Entonces, «se apoyó en la lanza para contemplar aquella visión, pues la sangre y la nieve juntas le recuerdan el fresco color que hay en el rostro de su amiga y piensa tanto que se queda ensimismado» (Chrétien, 2013: 527). Perceval pasa toda la mañana contemplando en esas gotas a Blancaflor, como suspirará Dante por la angelical Beatriz, Petrarca por su madonna Laura o don Quijote por la sin par Dulcinea. Perceval es ya un caballero ejemplar, impulsado en sus hazañas por el amor de su dama. Como en el amor de lonh del trovador Jaufré Rudel, la lejanía de Blancaflor ha ahondado el amor de Perceval por ella. De la presencia física ha pasado a la visión metafórica y, de esta, a la contemplación espiritual.

Llega después Perceval, entre vítores, a la corte de Arturo. Todos le aclaman por los poderosos caballeros que ha vencido y los cautivos que ha enviado ante el rey. Pero una doncella grotesca aparece en la corte y cuenta públicamente la falta de Perceval en el Castillo del Rey Pescador, así como el torrente de desgracias que esto causará. Entonces

Perceval dijo otra cosa: que no dormiría en un mismo alojamiento dos noches en toda su vida ni oiría noticias de un extraño paso sin ir a él, ni de un caballero que más valga que otros caballeros o que dos sin que vaya a combatir con él, hasta que sepa a quién sirven con el Grial y hasta que haya encontrado la lanza que sangra de forma que le digan la verdad probada de por qué sangra; y no dejará de hacerlo por más esfuerzo que le cueste. (535-536)

La penúltima novela de Chrétien de Troyes, Lanzarote o el caballero de la carreta, era ya, como esta, una novela de la quête. Allí Lanzarote arrostraba todo tipo de peligros y humillaciones para buscar y rescatar a su amada: la reina Ginebra. Cirlot, reflexionando sobre la quête, señala la relación entre el verbo buscar (querre) y el verbo latino del que deriva (quaerere), que significa preguntar. Para Cirlot, en estas novelas de Chrétien se concibe «la vida como búsqueda» (Cirlot, 214: 21) y «la búsqueda como forma de vida» (23). Además, a diferencia de los cantares de gesta, donde los héroes actúan acompañados de ejércitos, aquí el héroe afronta aislado los peligros.

8. Ortega y Gasset, hablando de los libros de caballerías inspirados - en buena parte- en la novela artúrica, define la aventura como «lo imprevisto, lo impensado, lo nuevo. Cada aventura es un nuevo nacer del mundo, un proceso único» (1914: 166). Y valora la incesante búsqueda de aventuras en don Quijote: «Esta voluntad se halla plena de una decisión: es la voluntad de la aventura. Don Quijote, que es real, quiere realmente las aventuras. Como él mismo dice: "Bien podrán los encantadores quitarme la ventura, pero el esfuerzo y el ánimo es imposible” » (172). 
En la novela cortés, el héroe parte solo, como caballero errante en búsqueda de aventuras. Aflora aquí una «nueva conciencia del individuo» y se inaugura un nuevo espacio en la literatura: «el espacio de la interioridad» (21).

En El cuento del Grial la quête ha asumido un nivel mucho mayor de abstracción y espiritualidad. Perceval no parte — como Lanzarote - en busca de una persona amada, sino del objeto que contiene y simboliza la fuente última del amor. Porque la lanza que sangra remite a la lanza de Longinos. Y el Grial es en la novela de Chrétien, según explicará luego un ermitaño, el recipiente que contiene la hostia que llevan cada día al padre del Rey Pescador. El Grial, de modo análogo al Arca de la Alianza veterotestamentaria, es el receptáculo de lo más sagrado: la casa de Dios. De ahí que Cirlot defina el Grial como «el objeto de búsqueda absoluto» (2014: 22), y que el medievalista francés Pauphilet afirmara: «El Grial es la manifestación novelesca de Dios. la búsqueda del Grial, por tanto, no es, bajo el velo de la alegoría, más que la búsqueda de Dios, más que el esfuerzo de los hombres de buena voluntad hacia el conocimiento de Dios» (García Gual, 2018: 142).

\section{Extravío y conversión del héroe}

Tras el compromiso de Perceval de dedicar su vida a la búsqueda del conocimiento sobre la lanza y el Grial, el narrador abandona al héroe para ocuparse de las aventuras de otro caballero artúrico: Galván, modelo de caballero mundano y cortés. En una de sus aventuras, el rey de Escavalón pide a Galván que «vaya a buscar la lanza cuyo hierro sangra siempre, pues está escrito que llegará un día en que todo el reino de Logres, que antaño fue la tierra de los ogros, será destruido por esa lanza» (Chrétien, 2013: 556). Él, sobre un relicario precioso, «jura que pondrá todo su esfuerzo en buscar la lanza que sangra» (556). Podría interpretarse que en las narraciones mitológicas el objeto mágico, el tesoro o la princesa virginal simbolizan el conocimiento, custodiado por el dragón del caos: oculto en la realidad prometedora — pero también amenazante- de todo lo desconocido. Y que es necesario estar dispuesto a afrontar los peligros de lo incierto para obtener el conocimiento (en este caso, la lanza sagrada) que permita reconfigurar la realidad.

Tras el juramento de Galván de buscar la lanza, volvemos a saber de nuestro héroe:

Perceval, eso cuenta la historia, había perdido la memoria de tal forma que no se acordaba ya de Dios. Cinco veces pasó abril y mayo, eso son cinco años enteros, que no adoró a Dios ni a su Cruz en iglesia o en monasterio. Así permaneció los cinco años y no por eso dejó de buscar hechos de armas; iba buscando las aventuras extrañas, las crueles y las difíciles, y las encontraba de forma que se portó muy bien y nunca emprendió cosa tan dura que no la llevara a cabo bien. Y durante los cinco años envió a cincuenta caballeros de renombre prisioneros a la corte del rey Arturo. (557)

Ortega y Gasset señala que la vida humana, para no perderse en el laberinto caótico de sí misma, debe estar entregada y orientada a un quehacer valioso: «Vivir es ir disparado hacia algo, es caminar hacia una meta» (1966: 127). La naturaleza teleológica de la existencia humana inspira los tópicos literarios de la vida como viaje (peregrinatio vitae) y de la persona como caminante (homo viator) e inspira también la construcción mítica de sentido. Porque, como subraya Peterson, «we are aiming, always, at an ideal» (1999: 416). De ahí que el mapa de sentido que dibujan los mitos sirva para orientar éticamente al ser humano hacia una meta ideal, hacia un estado subjetivo de perfección, hacia un futuro deseado. En última instancia, el mapa mítico de sentido responde a estas preguntas: 
1) What is? What is the nature (meaning, the significance) of the current state of experience?

2) What should be? To what (desirable, valuable) end should that state be moving?

3) How should we therefore act? What is the nature of the specific processes by which the present state might be transformed into that which is desired? (Peterson, 1999: 13).

La Comedia de Dante inicia la víspera del Viernes Santo, con el protagonista «perdido en una selva oscura, extraviado del buen camino» (Dante, 2018: 46). La novela de Chrétien nos muestra ahora, igualmente, a un Perceval perdido en una maraña de aventuras deslavazadas. Sigue realizando proezas, como había prometido cuando se comprometió a buscar el Grial. Pero ha perdido de vista el ideal trascendente, su meta última: la búsqueda de la verdad sobre la lanza y el Grial. Se ha convertido en un caballero mundano más, entregado a los hechos de armas, en busca de reconocimiento social (por eso envía los caballeros derrotados a la corte). Perceval ha incurrido de nuevo en la hamartía ( $\dot{\alpha} \mu \alpha \rho \tau i ́ \alpha)$, término que significa etimológicamente «errar el blanco», y que emplea Aristóteles en su Poética para referirse al «fallo» del héroe que desencadenará la tragedia. ${ }^{9}$ La palabra abarca desde un error no intencionado hasta una infracción moral, por lo que será utilizado con frecuencia en el Nuevo Testamento para referirse al pecado.

Y justamente en Viernes Santo, mientras «iba cabalgando por un yermo», Perceval encuentra a cinco caballeros y diez damas penitentes, que caminan descalzos. También fueron cinco los caballeros que encontró siendo un muchacho, en la Yerma Floresta, y cuya visión le despertó de su paraíso infantil y le espoleó a convertirse en caballero. Paralelo a ese primer momento climático,

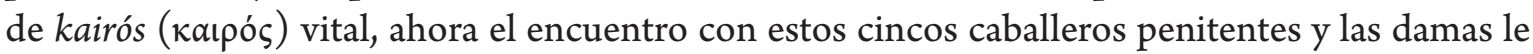
despierta de su vida caballeresca mundana y le espolea a convertirse en un caballero cristiano: un miles Christi. No olvidemos que las novelas de Chrétien se inscriben en la época de las cruzadas. Y que Bernardo de Claraval, maestro del Císter y predicador de la Segunda Cruzada, había encomiado hacia 1130, en su Elogio de la Nueva Milicia Templaria, a quienes combaten «contra los hombres de carne y hueso y contra las fuerzas espirituales del mal» (Herrán Alonso, 2005: 881). Para San Bernardo, canonizado en 1174 (mientras Chrétien escribe sus novelas), el templario reunía en sí las figuras antes opuestas del orator y el bellator: el que reza y el que combate.

A los caballeros penitentes les extraña que Perceval lleve puestas sus armas un Viernes Santo. Y es que este «no tenía ninguna preocupación del día ni de la hora ni del tiempo, tan afligido tenía el corazón» (Chrétien, 2013: 557). Los penitentes le cuentan que vienen de confesarse con un santo ermitaño. Tras despedirse de ellos, Perceval, llorando por su falta, se presenta ante el santo varón, y «sujeta al ermitaño por el pie, se inclina ante él, junta las manos y le ruega que le dé consejo, pues tiene gran necesidad» (559). Perceval, en su confesión con el ermitaño, declara: «hace bien cinco años que no sé dónde he estado, y no he amado a Dios ni he creído en Él, y desde entonces no he hecho nada más que daño» (559). Cuando el ermitaño le pregunta por qué ha actuado así, Perceval le cuenta su silencio ante el paso de la lanza y el Grial: «Y con el Grial que vi allí no sé a quién se sirve, y desde entonces lo he sentido tanto que me hubiera gustado estar muerto, y me olvidé de Nuestro Señor Dios» (559).

El ermitaño, al oír el nombre de Perceval, le cuenta que él es tío materno suyo, y refrenda que su silencio ante el cortejo del Grial se debió al pecado de abandonar a su madre desmayada. Además, le cuenta a Perceval que es sobrino del Rey Pescador, que su padre también es tío materno de

9. Hablando de la tragedia, afirma Aristóteles: «Necesariamente, pues, una buena fábula [...] no ha de pasar de la desdicha a la dicha, sino, al contrario, de la dicha a la desdicha; no por maldad, sino por un gran yerro, o de un hombre cual se ha dicho, o de uno mejor antes que peor» (Aristóteles, 1999: 170-171). 
Perceval y que lleva quince años recluido en una habitación del castillo del Grial, sin comer otra cosa que la hostia que le llevan en el Grial: «Tan santa cosa es el Grial; y es algo tan espiritual que su vida no la sostiene más que la hostia que va en el Grial» (560). El ermitaño pide a Perceval que se arrepienta de su pecado y le impone como penitencia acudir todos los días al monasterio a rezar, así como comer, durante los dos días antes de la Pascua, el mismo alimento que el ermitaño. Perceval «adoró la Cruz y lloró sus pecados y se arrepintió humildemente [...]. En Pascua comulgó Perceval con gran humildad» (561). A través de esta confesión (ya más interiorizada y subjetiva que en siglos pasados), ${ }^{10}$ el héroe desarrolla su metanoia ( $\left.\mu \varepsilon \tau \alpha v o เ \alpha\right)$, su «cambio de mente» (aunque el término se emplea en el Nuevo Testamento también como «arrepentimiento»). Esa conversio, ese giro o transformación espiritual de Perceval, tiene su culmen en la comunión en el día de Pascua, el día central del calendario litúrgico cristiano, que celebra la resurrección de Cristo y, a través de ella — como en el ave Fénix - simboliza la muerte y el renacimiento espiritual. Este episodio climático, de enorme significado psicológico, será la última ocasión en que aparezca Perceval en la novela. ${ }^{11}$

Lo desconocido asusta porque su rango de significación es ilimitado: desde lo mejor que pueda imaginarse, hasta lo peor (una muerte dolorosa, por ejemplo). Según argumenta Peterson, para representar las actitudes ante lo desconocido la mitología ha desarrollado «two transpersonal patterns of behavior and schemas of representation, constituting the individual as such, embodied in mythology as the "hostile brothers" (1999: 307). Un hermano es el héroe: dispuesto a afrontar con valentía lo desconocido, con la esperanza de que podrá extraer de lo ignoto conocimientos creativos, que actualicen la sociedad, la pacifiquen y la salven de la decadencia. Su otro hermano es el eterno adversario, el cual, ante la imposibilidad de comprender la complejidad del mundo, se retrae en sí mismo y rechaza el contacto con lo que no entiende. El adversario niega la existencia de lo desconocido, encastillándose, de manera rígida y estática, en su conocimiento limitado. Para Peterson:
Absolute identification with the «known» necessarily comes to replace all opportuni- ty for identification with the process that comes to know. The presumption of absolute knowledge, which is the cardinal sin of the rational spirit, is therefore prima facie equiva- lent to rejection of the hero-to rejection of Christ, of the Word of God, of the (divine) process that mediates between order and chaos. The arrogance of the totalitarian stance is ineradicably opposed to the «humility» of creative exploration. [...] The devil is the spirit who eternally states, «all that I know is all that there is to be known»; the spirit who falls in love with his own beautiful productions and, in consequence, can no longer see beyond them. (1999: 316) ${ }^{12}$

\footnotetext{
10. Jung destaca la importancia de la confesión católica, situando su mecanismo de preguntas y respuestas como una de las fuentes de inspiración del psicoanálisis. En la confesión, su «fisonomía y significado fueron adaptados desde un principio a la naturaleza de los contenidos inconscientes». El diálogo, estimulado por preguntas hondas, sobre problemas vitales, confiere a la confesión una «enorme eficacia», puesto que el sacerdote «está perfectamente capacitado para poner fin a la tormenta que él mismo ha desatado» (Jung, 2008: 367). Podría entenderse la confesión, desde la teoría junguiana, como el ámbito en el que el confesado, despojándose momentáneamente de su «Persona», de su máscara social (el acuerdo entre el ego y la sociedad), puede volver consciente —y por tanto, tratable - su «sombra».

11. Tras la comunión de Perceval, leemos: «El relato no habla aquí más de Perceval, sino que oiréis hablar bastante de mi señor Galván, antes de que volváis a oír contar nada de él» (Chrétien, 2013: 561). El relato, como es sabido, quedará inacabado por la muerte del autor.

12. También Albert Camus señala la ligazón entre orgullo cognoscitivo y tiranía al afirmar en 1948: «Ceux qui prétendent tout savoir et tout régler finissent par tout tuer» (2006: 464).
} 
La pareja antitética de hermanos, ejemplificada en las deidades egipcias de Osiris y Seth, o en los primeros hermanos bíblicos (Abel y Caín), aparece en el mapa de sentido cristiano en la oposición entre Jesús y Satán, que en hebreo significa adversario, enemigo o acusador. Es también interesante, a este respecto, la etimología de Lucifer (el portador de la luz), que se asocia con el orgullo del ángel caído por soberbia. En El cuento del Grial no hay un adversario humano o sobrenatural importante que se oponga al héroe. Los caballeros con los que se enfrenta Perceval no llegan nunca a causarle estragos. El adversario está internalizado: habita en la conciencia del héroe. Es la tentación que experimenta, tras su fracaso ante el Grial, de ocultar su falta y abandonar la búsqueda trascendente. Es la voz interior que sugiere no reemprender la búsqueda del Grial, sino distraerse en aventuras caballerescas sucesivas (como las conquistas del Don Juan) y gloriarse en sus triunfos mundanos.

De hecho, como hemos visto, Perceval ha llegado a perder el camino durante cinco años. Tras su silencio ante el Grial se ha sumido en la desesperanza ( $\ll$ lo he sentido tanto que me hubiera gustado estar muerto») y ha emprendido una huida hacia adelante, dispersándose en incontables aventuras y distracciones (el divertissement pascaliano), acaso para olvidar lo esencial. Se ha volcado en lo inmediato, en lo fragmentario, obrando arbitrariamente, sin una meta integradora. Perceval no es un héroe porque yerre poco. A lo largo de su vida, se equivoca abandonando a su madre desmayada, besando forzadamente a una dama, hablando neciamente en la corte, callando ante el Grial u olvidando durante cinco años su búsqueda trascendente. Y es que la vulnerabilidad no es incompatible con el heroísmo. Como señala Peterson: «Acceptance of mortal weakness is the paradoxical humility that serves as precondition for true heroism. [...] Humility means, therefore: I am not yet what I could be» (1999: 333). Perceval es un héroe porque reconoce sus faltas con humildad y busca consejo; porque desea siempre aprender y perfeccionarse; y porque es capaz de adentrarse con valentía en el caos, en el bosque oscuro de lo desconocido, para extraer de allí conocimiento que adapte, reordene y mejore el mundo.

\section{Conclusión: Perceval, héroe exploratorio}

Hemos seguido el periplo vital de Perceval en El cuento del Grial, interpretándolo desde el marco teórico de Jordan Peterson. La infancia paradisíaca del muchacho en la Yerma Floresta Solitaria, cercado por el amor devorador de la Dama Viuda. El encuentro epifánico con los cinco caballeros, que le espolea a abandonar la casa materna. El internamiento en el bosque oscuro, símbolo del caos y lo desconocido. La acogida paternalista en la corte de Arturo, el rey sabio, representación del Gran Padre: del orden y la cultura. El aprendizaje del muchacho (su asimilación de la identidad grupal nobiliaria), avivado por su encendido deseo de conocer. El castillo del Rey Pescador y el silencio calamitoso del joven ante el cortejo del Grial. La autoconciencia de Perceval, descubriendo su propio nombre. La contemplación de la amada Blancaflor en las gotas de sangre en la nieve. La promesa del héroe de embarcarse en una búsqueda perpetua. El extravío de Perceval, olvidándose durante cinco años del ideal trascendente. La conversión o metanoia del héroe: su cambio de mente y arrepentimiento, manifestados en la confesión, la penitencia y la comunión el día de Pascua.

Perceval comete muchos errores a lo largo de su vida. Pero el error no es el mal. Como deslinda Peterson, «evil is rejection of and sworn opposition to the process of creative exploration. Evil is proud repudiation of the unknown, and willful failure to understand, transcend and transform 
the social world $\gg(1999: 310)$. El mal corrosivo es la soberbia, el envanecimiento en las cualidades personales, que lleva a ignorar los propios errores y a descartar la información que contradice las asunciones previas. Un siglo después de la muerte de Chrétien, Tomás de Aquino definirá la soberbia como el primero y principio de todos los pecados, y el más grave en sí mismo. ${ }^{13} \mathrm{El}$ error, si se asume con humildad, es una magnífica ocasión para aprender, para recabar nueva información y adaptar las propias asunciones y comportamientos a la realidad. Es una oportunidad para adaptarse evolutivamente al cambio constante del mundo. De ahí que Peterson afirme que «error is the mother of all things» (341) y que, en la línea socrática, «the fool is the truth» (333). Solo quien es consciente de su propia ignorancia y falibilidad puede, explorando el mundo con humildad, alcanzar la sabiduría.

Desde su posición inicial de ignorancia sobre el mundo (son muchos los que llaman al muchacho necio), a través de la pasión por el conocimiento y la humildad, Perceval no solo se convierte en un caballero cortés modélico. No solo derrota a otros caballeros en duelos individuales, envía cautivos a la corte y honra a su amada. Es capaz, también, de rebasar y actualizar su entorno cultural. Su vivencia de la caballería asume una dimensión trascendente, como miles Christi. Pero no lo hace al modo cruzado, siguiendo el modelo de las órdenes militares creadas en su último siglo. No busca Perceval la conquista violenta y colectiva de Tierra Santa. Busca la conquista pacífica y personal del conocimiento trascendente (simbolizado en el enigma de la lanza que sangra y el Grial), que renueve -que salve- al individuo y la sociedad. Y es que, como apunta Peterson al hablar de la indagación de los alquimistas, «exploration of the unknown and forbidden meant generation of redemptive knowledge» (1999: 422).

El conocimiento que busca Perceval en su quête incansable podrá sanar a su tío, el Rey Pescador (inválido desde que «fue alcanzado por una jabalina entre los dos muslos») y devolver la lozanía a sus tierras. $Y$, al hacerlo, por desplazamiento metafórico, estará de algún modo redimiendo a su difunto padre, quien también «fue herido entre las piernas de tal modo que quedó tullido en el cuerpo» y perdió sus tierras. El héroe exploratorio, armado con el nuevo conocimiento, «journeys to the underworld to rescue his incapacitated ancestors» (Peterson, 1999: 90), «rescues his dead father from the underworld, and revivifies him» (179). El ejemplo mitológico más célebre es el relato egipcio en el que Horus derrota a Seth, su tío asesino, y devuelve la vista y el trono a su difunto padre Osiris. Pero también podrían mencionarse los dos hijos de Noé que cubren su desnudez; o al último de los tres hijos que, en un cuento de hadas de los Hermanos Grimm, cura a su padre de una enfermedad mortal, tras encontrar el agua mágica. ${ }^{14}$

Siguiendo el esquema de representación mitológica que plantea Peterson, Perceval es en esta novela el héroe exploratorio, el conocedor, que se aventura en el mundo de lo desconocido (lo inexplorado, el caos, la Naturaleza, la Gran Madre), para extraer conocimiento. Como todo héroe, al afrontar lo desconocido -el dragón del caos-arriesga en el proceso su integridad física y moral. Lo vemos, durante cinco años, perdido, olvidado de Dios y de su búsqueda trascendente. Su humildad, su apertura cognoscitiva, le salvan. Reconoce su ignorancia y su extravío, y pide consejo al sabio ermitaño. Renace espiritualmente. Y, aunque no sabemos más de él (por dejar Chrétien su novela inacabada), imaginamos que continuará buscando la lanza y el Grial, incansable, hasta

13. Cfr. Suma Teológica, II-IIae, c. 162.

14. El cuento se titula «El agua de la vida». Se pueden encontrar paralelos en otros cuentos folclóricos, como en el relato escocés «El oso pardo de Green Glen», recopilado por el celtista John Francis Campbell en Popular Tales of the West Highlands (1862). También cabe citar el libro de Carlo Collodi, Las aventuras de Pinocho (1883), en el que el niño-marioneta rescata a su padre del vientre de la ballena, muriendo casi en el intento. 
que, al encontrarlos, cure la invalidez del Rey Pescador y devuelva la fecundidad a sus tierras; hasta que, metafóricamente, redima a su padre de su muerte desgraciada y haga reverdecer las tierras de la Yerma Floresta. De este modo Perceval, el héroe explorador, el conocedor, podrá actualizar y revitalizar lo ya conocido (lo explorado, el orden, la Cultura, el Gran Padre), transformándolo con su conocimiento redentor.

\section{Bibliografía}

Adolf, Helen (1960), Visio Pacis, Holy City and Grail. An Attempt at an Inner History of the Grail Legend, University Park, The Pennsylvania State University Press.

Aristóteles (1999), Poética, ed. V. García Yebra, Madrid, Gredos.

Blumemberg, Hans (2003), Trabajo sobre el mito, trad. Pedro Madrigal, Barcelona, Paidós.

Calvino, Italo (2015), Por qué leer a los clásicos, trad. Aurora Bernárdez, Madrid, Siruela.

Camus, Albert (2006), Euvres complètes. II. 1944-1948, París, Gallimard.

Chrétien de Troyes, Obras completas, ed. Carlos Alvar, Barcelona, Edhasa, 2013.

Cirlot, Victoria (2007), Figuras del destino: mitos y símbolos de la Europa medieval, Madrid, Siruela.

(2014), Grial. Poética y mito (siglos XII-XV), Madrid, Siruela.

Dante Aliguieri (2018), Divina Comedia, ed. J. M. Micó, Barcelona, Acantilado.

García GuAL, Carlos (1986), «El héroe de la búsqueda del Grial como anticipo del protagonista novelesco (Reflexiones sobre un tema medieval) $\gg$, Epos: Revista de Filología, 2, pp. 103-114. (2018), Historia del rey Arturo y de los nobles y errantes caballeros de la Tabla Redonda, Madrid, Alianza.

Herrán Alonso, Emma (2005), «La configuración literaria del tópico del 'Miles christi' entre la Edad Media y el Renacimiento», en Actes del x Congrés Internacional de l'Associació Hispànica de Literatura Medieval, Alicante, Universitat d'Alacant, pp. 879-893.

Jung, Carl G. (1970), Arquetipos e inconsciente colectivo, trad. Miguel Murmis, Barcelona, Paidós. (2008), Obra Completa, vol. II: Acerca de la psicología de la religión occidental y de la religión oriental, trad. Rafael Fernández de Maruri, Madrid, Trotta.

Nietzsche, Friedrich (2001), Más allá del bien y del mal. [Preludio de una filosofía del futuro], trad. Andrés Sánchez Pascual, Madrid, Alianza.

Ortega y Gasset, José (1914), Meditaciones del Quijote, Madrid, Publicaciones de la Residencia de Estudiantes.

(1966), La rebelión de las masas, Madrid, Espasa-Calpe.

Peterson, Jordan B. (1999), Maps of Meaning. The Architecture of Belief, Nueva York y Londres, Routledge.

RiQuer, Martín de (1968), La leyenda del Graal y temas épicos medievales, Madrid, El Soto.

SAFRANSKI, Rüdiger (2012), Romanticismo. Una odisea del espíritu alemán, trad. Raúl Gabás, Barcelona, Tusquets. 